\title{
Social Wellbeing of Elderly People in Russia
}

\author{
Elena A. Frolova ${ }^{1, a}$ and Veronika A. Malanina ${ }^{1}$ \\ ${ }^{1}$ National Research Tomsk Polytechnic University, 634050, Lenin av., 30, Tomsk, Russia
}

\begin{abstract}
This paper describes the results of the research in the field of measurement and evaluation of the elderly's social wellbeing. The main characteristics of international methods for evaluating older people's wellbeing are critically discussed. The paper also contains some preliminary results of the sociological survey on wellbeing of the elderly conducted in Tomsk city (Siberia, Russia). Social factors, such as communication with other people, family care, providing support for friends and neighbours play the most important role in social wellbeing of elderly population. The lack of social connectedness is a key reason for life dissatisfaction among large proportion of the elderly in Russia. We have found bilateral correlation between subjective life satisfaction and willingness to help other people: happier elderly people are more likely to help even outside families; people providing help are more likely to be happier in general compared to those who don not. Income also correlates positively with the readiness to help. The research is based on the OECD, European Social Survey, National statistics of the UK, Active Ageing Index databases as well as articles and monographs and the results of sociological survey of Tomsk elderly population.
\end{abstract}

\section{Introduction}

The quality of life and wellbeing studies are a cuttingedge socio-economic research. These issues are topical due to objective economic and social changes. Wealth and welfare are supplemented by social, cultural and natural factors. In the second half of the XX century the world economy faced an active process of population ageing [1]. The proportion of the elderly in the age structure of society is constantly increasing. More than $25 \%$ of the world population will fall into the category of the elderly by 2050 [2]. Factors that contribute to life satisfaction and subjective wellbeing of elderly people still have not been thoroughly studied.

The main goal of our research is to characterize the nature of elderly population's social wellbeing. The objectives of the paper are to determine the essence and basic factors of wellbeing, to examine methods of wellbeing assessment and measurement, to identify social factors of wellbeing and describe the results of the elderly's social wellbeing assessment in Tomsk region. In our study we also used OECD, HelpAge International, National statistics of the UK and European Social Survey databases.

\section{Wellbeing assessment: theoretical background}

Human wellbeing is one of the most popular fields of modern multidisciplinary research. Subjective evaluation

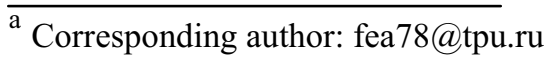

of the utility has revolutionized economics at the end of the XIX century. Subjective evaluation of life satisfaction and identification of its key factors are a new qualitative leap to be made by the economic science in the XXI century.

The report by the Commission on the Measurement of Economic Performance and Social Progress by J. Stiglitz, A. Sen, J. Fitoussi (2009) became an important starting point to increase interest towards subjective wellbeing issues. In this report, the authors noted that the traditional market-based indicators disregarded a wide range of social factors and thus did not allow an adequate comprehension of the quality of life. They recommended shifting the focus of understanding the progress of national economies from the productivity evaluation to wellbeing assessment [3].

The main part of the indicators, used in modern international techniques of wellbeing (or a quality of life) measurement, is based on the conjunction of subjective and objective assessments of the national economy and people's life [4]. Subjective wellbeing is based on individual evaluations of the quality of life [5]. Objective wellbeing is based on the approach which allows evaluating the degree of basic human needs satisfaction (food, housing, education, employment, health, security, freedom) [6]. In the same way, wellbeing assessment through a range of subjective and objective factors creates a cumulative effect [7]. Objective indicators reflect the real social and economic 
situation and subjective indicators allow calculating the valuable factors affecting the life of a person [8].

Human wellbeing is closely connected to people's preferences and social environment. These factors are significantly changing during life course and, thus wellbeing is commonly tied to human's age periods, such as wellbeing of children, wellbeing of youth, wellbeing of adults and wellbeing of the elderly, which are considered to be driven by similar factors, but having different importance during life course.

There are various methods of evaluating the wellbeing of the population - the Human Development Index (HDI), the International happiness index (Happy Planet Index), but these techniques assess the quality of life of the population as a whole, while specific indicators are required for the correct evaluation of the quality of elderly people's lives, in particular.

Growing interest in the measurement and evaluation of the wellbeing of the elderly is related to the objective trends of population ageing. The intensity of ageing is particularly high in the most developed countries. Ageing is equally a sign of the overall level and quality of life improvement and a potential threat to the stability and security of national economy. The elderly person is a primary voter, a key consumer and assets holder, thus the elderly's wellbeing is a key factor of improving the wellbeing of the whole world's population in the future.

So, it is important to assess the overall elderly population's life satisfaction, and to evaluate their economic and social status. An active ageing lifestyle is a "cure" not only for those elderly who have objective physiological limitations, but also for mental and social health of society.

There are some international methods to measure wellbeing of older adults in global economy, such as:

1. Global Age Watch Index.

2. Life Opportunities Survey.

3. Older Americans: key indicators of wellbeing.

4. Better Life Index.

5. Active Ageing Index.

6. Other national indicators.

Global Age Watch Index includes 13 indicators combined into four key areas of wellbeing: income security, health status, employment and education, enabling environment [9]. The global ranking of countries shows that the elderly are doing best in Nordic, Western European, North American and some eastern Asian and Latin American countries. Russia ranks only 78 out of 91 countries. The key factors of the older adults' wellbeing in Russia, according to the survey, are employment and education, income security and health status. However, these four groups of factors in the wellbeing leading countries (Sweden, Norway, Germany, the Netherlands and Canada) are equally important.

Older Americans 2012 (Federal interagency forum on ageing related statistics) used $37 \mathrm{key}$ indicators of wellbeing including indicators that describe the main features of the elderly (the number of elderly people in the country, age, racial and ethnic characteristics, marital status, etc.), economic characteristics (income, poverty, employment), health status (mortality, morbidity, functional limitations), risks for health and lifestyle (vaccination, physical activity, pernicious habits), health (health insurance, social services and special equipment) [10].

Office for National Statistics (the UK) elaborates the Life Opportunities Survey. The survey is based on assessing income and housing conditions, medical care quality satisfaction, the level of physical and labour activity, including community participation and prosocial activities of the elderly. Every aspect is published as a separate report, which includes a statistical database and an analytical report [11].

Measuring wellbeing "How's Life?" index includes description of methodologies for assessing the wellbeing by the individual parameters, the description of an interactive shell for the collection, processing and presentation of research results. It is based on the methodology developed by the OECD Better Life Index and is calculated on the basis of household income, work, community, education, environment, civil society, health, life satisfaction, safety, free time. Moreover, the interactive form allows comparing personal preferences of each site visitor ratings in the country as a whole, in their age [12].

Active Ageing Index - (AAI) - is a relatively new methodology, developed by experts in the field of ageing in 2012 for the comparative assessment of the socioeconomic activity and quality of life of the elderly people in European countries [8, 13, 14]. Some international organizations, namely the Council of Europe and Economic Commission for Europe contribute to Active Ageing Index (AAI) development. According to AAI, the wellbeing of the elderly is assessed on the basis of 22 indicators, grouped into four domains: employment, participation in society, independence, healthy and secure living and capacity and enabling environment for active ageing. Most of the sub-indices of each domain are measured as subjective reports and evaluations of respondents.

Comparative analysis of international methods for the elderly's wellbeing measurements allows coming to conclusion: social factors of subjective wellbeing are widely represented in the studies and have a great impact on overall wellbeing assessment. However, there is a lack of data and evidence about social wellbeing of elderly people in Russia. Also, we can observe a considerable methodological challenge of taking subjective evaluations into account in assessment of elderly people wellbeing.

\section{Methods}

The Russian elderly's wellbeing research is still fragmented. It is represented mainly by sociological surveys and psychological research. There are no integrated methods for evaluating lifelong wellbeing of the elderly in Russia. To fill this gap, the research team of the International Scientific Educational Laboratory for the Improvement of Wellbeing Technologies of Elderly Population and researchers from the Department of Sociology, Psychology and Law of National Research 
Tomsk Polytechnic University have designed a questionnaire to explore the important parameters of the elderly's wellbeing in Russia. Some key indicators of the international methodologies were also used as basic parameters of wellbeing. The questionnaire consists of 37 questions, grouped by main blocks: financial status and property, health and physical activity, social capital and social activity, computer skills.

The survey was carried out in 2014 and involved 585 respondents, including $32.5 \%$ - men, $67.5 \%$ - women. Over $48 \%$ of the sample are people of $60-70$ years old, $23 \%$ of participants are $50-60$, over $28 \%$ are older than 70 . Only $23,1 \%$ of respondents are living alone, the rest of the respondents are living with a spouse, parents, children, grandchildren or other relatives or nonrelatives. Over $50 \%$ of respondents mentioned salaries as one of the sources of income, thus we can observe high activity of the Russian elderly on the labour market in Tomsk

\section{Results and discussion}

Social factors are integral components of wellbeing in all global and national methodologies and they are especially important for the older people. This conclusion was confirmed in the framework of Tomsk survey.

In Tomsk survey, the respondents were asked to range three most important factors of social wellbeing. It was necessary to rank their importance. More than $70 \%$ of respondents put first such priority as communication with family and friends. The importance of communication factor is much more pronounced than the importance of financial prosperity. The importance of social factors is confirmed by the willingness and readiness to help someone, even when the elderly have significant limitations in performing everyday activities. This fact indicates the priority of social relations between individuals.

Moreover, we have noticed a significant trend: the potential willingness to help people is positively correlated with income among elderly people in Tomsk (Figure 1).

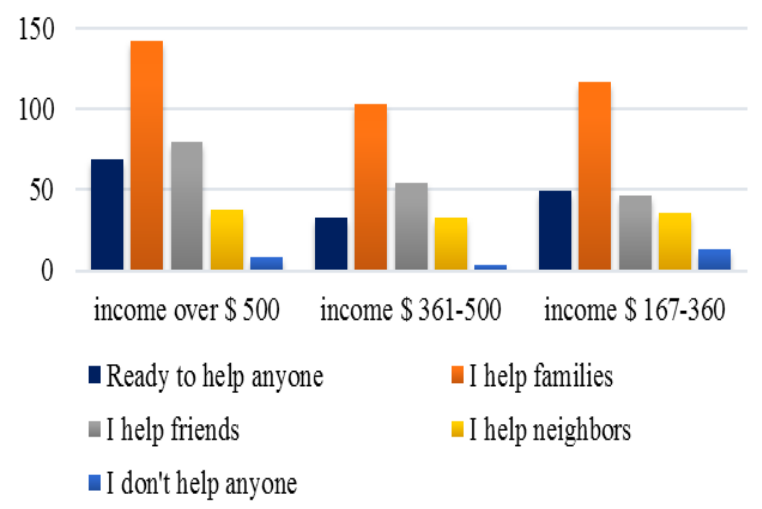

Fig. 1. Readiness to help and income correlation

This fact indicates an on-going change in social relations between individuals. A higher degree of financial prosperity allows creating extensive social capital networks and it can be the outcome of high social capital. As we have mentioned, the majority of the "young" elderly aged 50-60 is still working and thus involved in social networks outside families. The person with low income (prevailingly non-working) can help only families, refusing or simply being unable to help someone else. Social relationships are largely concentrated among relatives (inner circle) when income decreases. Again, income and readiness to help may have two-way causal relationship, or may not have any, since pro-social behaviour may be based upon altruism, habit or expected social acceptability of individual actions [15].

The group of respondents who does not help anybody is growing as income decreases. They also do not rely upon support from friends or neighbours while the family's resources are limited. The share of those who help friends falls with income decrease. Still, the elderly with high income and low income tend to help families more than elderly people with middle income, though high-income group may be more responsive due to the ability to help, and low-income group due to empathy. Another explanation is that "help" can be interpreted differently by people with high and low income due to having different background and current circumstances they live in (education, working and financial status).

We should also note the correlation between the feeling of happiness and willingness to help others. Happier people are more willing to help their surroundings (Figure 2).

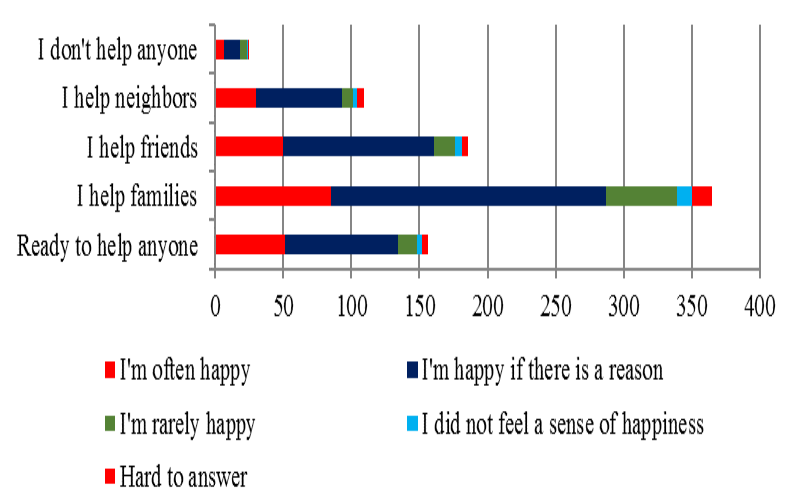

Fig. 2. Happiness and help correlation

The correlation between the degree of subjective satisfaction with life and social activity is similar to the previous indicators: most elderly respondents who provide help to other people are generally more satisfied with their lives. Their readiness to help other people correlates positively with the degree of subjective satisfaction (Figure 3). 


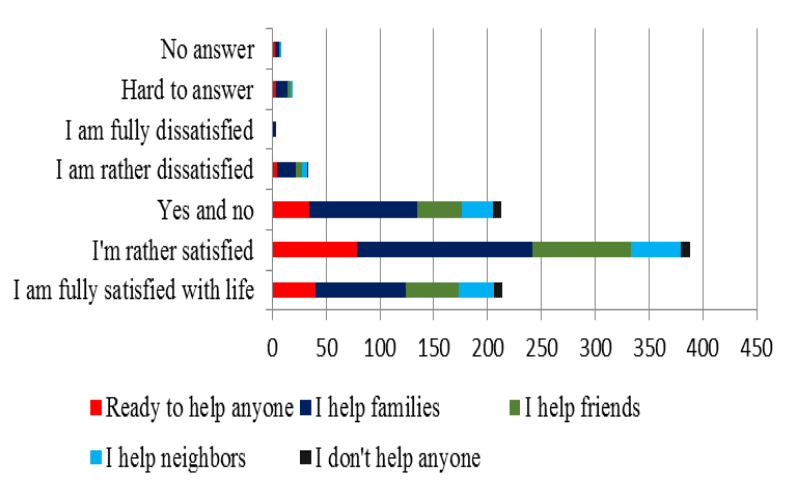

Fig. 3. Life satisfaction and help correlation

People who provide help are significantly more satisfied with life, compared with groups of the elderly who only expressed willingness to assist or help neighbours. Higher financial prosperity allows creating or indicating more extensive social capital networks, which, in turn, requires and provides help. Social networks engagement as a help-giver or help-beneficiary promotes subjective wellbeing of the elderly. Social connectedness can be limited after retirement affecting negatively the subjective wellbeing. Relevant policy applications to support subjective wellbeing of the elderly people may imply more gradual retirement or psychological support during a pre-retirement and early retirement period [16].

\section{Conclusion}

Wellbeing is a subjective satisfaction of an individual with life. There are numerous factors that define this satisfaction, but it is crucial to identify and measure the importance of each parameter for the person, not only a quantitative measurement of various indicators. Social factors play a key role in ensuring the subjective satisfaction both within the values upheld by the individuals and in their everyday activities. Social factors significantly improve the wellbeing of the elderly, so we can conclude that social wellbeing is a separate component of lifelong wellbeing. Social activity may be dependent upon the financial status of the individual, as well as upon marital status and health. But the last two hypotheses require additional verification as well as a study of correlations between various social factors.

Social activity is necessary for supporting the emotional wellbeing. It compensates inaccessible or diminishing professional activity for the elderly. It allows individuals to feel needed, forming positive expectations for the future and self-esteem. The results of the sociological survey in Tomsk show the positive correlation between income and readiness to help, happiness and help, life satisfaction and help. Social networks inclusion contributes to successful life of the elderly helping them to remain active, socially-oriented, healthy, optimistic, satisfied with their position in society and their way of life, and they have positive expectations for the future.

\section{Acknowledgment}

This work was performed by the authors in collaboration with Tomsk Polytechnic University within the project in Evaluation and enhancement of social, economic and emotional wellbeing of the elderly under Agreement No.14.Z.50.31.0029

\section{References}

1. Lloyd-Sherlock, P. Population Ageing and International Development. (The Policy Press. University of Bristol, 2010)

2. Global Age Watch Index 2014. Age Watch report card: Russian Federation. Available at: http://www.helpage.org/globalagewatch/population-ageing-data/countryageing-data/? country $=$ Russian $\% 2 \mathrm{BFederation}$ [Accessed: 15.07.2015]

3. Report by the Commission on the Measurement of Economic Performance and Social Progress. Available at: http://www.stiglitz-senfitoussi.fr/documents/overview-eng.pdf/ [Accessed: 15.03.2015]

4. V. La Placa, A. McNaught, A. Knight, International Journal of Wellbeing. 36 116-12 (2013)

5. F. Sarracino, The Journal of Socio-Economics. 39 (4), $482-517$ (2010)

6. P. O'Reily, F. Caro, Journal of Ageing and Social Policy, 6(3), 39-71 (1995)

7. L. Camfield, L. Esposito World Development. 59, 212-223 (2014)

8. A. Zaidi, K. Gasior, M.M. Hofmarcher, O. Lelkes, B. Marin, R. Rodrigues, A. Schmidt, P. Vanhuysse, E. Zolyomi, Active Ageing Index 2012. Concept, Methodology and Final Results. (Research Memorandum/ Methodology Report, European Centre Vienna, 2013)

9. Global Age Watch Index 2013. Available at: http://www.helpage.org/download/52949d5814 95f/. [Accessed: 18.02.2015]

10. Older Americans 2012: Key Indicators of WellBeing. 2012. Available at: http://www.aoa.gov/agingstatsdotnet/Main_Site /Data/2012_Documents/Docs/EntireChartbook. pdf [Accessed: 10.01.2015]

11. Life Opportunities Survey. 2010. Available at: http://www.ons.gov.uk/ons/rel/los/lifeopportunities-survey/wave-two-interim-results2010-11/wave-two-interim-report.pdf [Accessed: 10.03.2015]

12. OECD Guidelines on Measuring Subjective Well-being. Available at: http://www.oecd.org/statistics/Guidelines $\% 20$ o $\mathrm{n} \% 20$ Measuring\%20Subjective\%20Wellbeing.pdf [Accessed: 13.02.2015]

13. A. A. Walker, International Social Security Review. (1), 121-139 (2002)

14. L. Foster, A. Walker, The Gerontologist 00, 1-8 (2014) 
15. E. Frolova, V. Malanina, The European Proceedings of Social \& Behavioural Sciences EpSBS. Available at: http://dx.doi.org/10.15405/epsbs.2016.02.54 [Accessed: 01.02.2016], 425-431 (2016)

16. D.A. Hershey, K. Henkens, The Gerontologist. 54 (2), 232-244 (2014) 